\title{
Nutritional Status and Associated Factors Among the Community-Dwelling Elderly Population in Debre Berhan Town, North Shewa Zone, Ethiopia
}

This article was published in the following Dove Press journal:

Nutrition and Dietary Supplements

\author{
Yordanos Mezemir (D) \\ Gudina Egata ${ }^{2}$ \\ Demelash Geset' \\ Abera Lambebo iD ${ }^{3}$ \\ 'Department of Public Health, Debre \\ Berhan Health Science College, Debre \\ Berhan, Amhara Regional State, Ethiopia; \\ ${ }^{2}$ School of public health, Addis Ababa \\ university, Debre Berhan University, \\ Addis Ababa, Ethiopia; ${ }^{3}$ Department of \\ Public Health, Debre Berhan University, \\ Debre Berhan Amhara Regional State, \\ Ethiopia
}

Background: Nutritional status of the elderly is one of the important determinants of their health and quality of life. However, there is limited evidence on the prevalence of malnutrition among the elderly population in Ethiopia.

Objective: To assess the nutritional status and associated factors among the communitydwelling elderly population, in Debre Berhan town, Ethiopia.

Materials and Methods: A community-based cross-sectional study design was used among a random sample of 347 elderly people living in Debre Berhan town, North Shewa, Ethiopia from April 1-30, 2020. Data were entered into Epi-Data version 3.1 and then exported to STATA14 for analysis. Multivariable ordinal logistic regression analyses were done after checking parallel line assumptions with the STATA command "ologit" and "gologit2" for POM and PPOM, respectively. And odds ratio along with 95\% confidence interval was estimated by "ologit" and "or". The level of statistical significance was declared at a $\mathrm{p}$-value of $<0.05$.

Results: A total of 341 elderly groups participated in this study with a response rate of $98.27 \%$. Out of this, $21.1 \%$, 95\% CI: $(16.4 \%, 25.2 \%)$ were malnourished and $49.3 \%, 95 \%$ CI: $(43.9 \%, 55.3 \%)$ were at risk of malnutrition. In multivariable ordinal logistic regression, for being at risk of malnutrition and being malnourished, the following variables were significantly associated; being male, $2.03(\mathrm{AOR}=2.03,95 \% \mathrm{CI}: 1.13,3.63)$, being aged above 75 years, $2.58(\mathrm{AOR}=2.58,95 \% \mathrm{CI}: 1.34,4.99)$, living with others, 3 (AOR $=3.00$, 95\% CI: 1.23, 7.05), not having a care giver, 2.21 (AOR=2.21, 95\% CI: 1.14, 4.27), lack of formal education, 2.06 ( $\mathrm{AOR}=2.06,95 \% \mathrm{CI}: 1.19,3.57)$, being in the low category of wealth index, 3.27 (AOR = 3.27, 95\% CI: 1.95, 5.5), having depression, 1.9 (AOR = 1.9, $95 \%$ CI: $1.22,2.94)$ and alcohol consumption, 1.77 (AOR $=1.77,95 \%$ CI: $1.04,2.99)$ were significantly associated.

Conclusion: One-fifth of the participants were malnourished and around half of the participants were at risk of malnutrition.

Keywords: malnutrition, risk of malnutrition, factors, elderly, Debre Berhan, Ethiopia

\section{Introduction}

The aging of the population (also known as demographic aging and population aging) is a term that is used to describe shifts in the age distribution (age structure) of a population toward people of older ages. A person's chronological age is the time since birth, normally measured as the exact number of years or the completed number of years. ${ }^{1}$
Correspondence: Abera Lambebo Debre Berhan University, PO BOX 445 Debre Berhan, Ethiopia

Tel +251910153058

Email lambebo70@gmail.com 
Some measures using the current age structure are based on the proportion of the population below a given chronological age or above a threshold considered "old," or ratios of these measures. For example, the potential support ratio frequently uses the chronological age of 65 years or other ages such as 60 or 70 years. $^{2}$ According to the world factbook of December 7, 2019 life expectancy of the total population in Ethiopia was 63 years in $2018 .^{3}$

According to United Nations reports of 2018, for the first time in history, persons aged 65 years or over, worldwide, will outnumber children under age five. Projections indicate that by 2050 there will be more than twice as many persons above 65 as children under five. ${ }^{4}$ And in the future old age would appear to be more exciting at this moment than any time in the past. $^{5}$

Globally, the estimated number of elderly people aged 65 and older is projected to grow from 524 million in 2010 to nearly 1.5 billion in 2050 and is incremental in developing countries.

As the elderly are the precious stone of society that is often overlooked and, therefore, needs to be preserved and respected, as they are the building blocks for the future generations. ${ }^{6}$ And aging is a multifaceted biological phenomenon, often conveyed by various socioeconomic variations that have a great impact on the nutritional status and needs of the elder individual. ${ }^{7}$ In addition to that, the incidence of malnutrition is increasing in this population. And it is associated with a decline in functional status, impaired muscle function, decreased bone mass, immune dysfunction, anemia and reduced cognitive function. ${ }^{8}$

Malnutrition in the elderly is demarcated as a state of miss consumption or inadequate nutritional status. ${ }^{9}$ Malnutrition is generally associated with various health problems such as pain, anxiety, and depression. ${ }^{10}$ On other hand, factors like feeding difficulty, reduced mobility, psychological distress, being widowed, illiteracy, caring for children, poverty, and poor access to health and social services make the elderly more vulnerable to malnutrition. ${ }^{11}$

Even though elderly people were a risk to malnutrition, there are limited studies on the assessment of nutritional status and factors among elderly individuals in Ethiopia. Again, this research can assess the nutritional status and risk factors associated with malnutrition in the community setting of Debre Berhan town.

\section{Materials and Methods}

A cross-sectional study was conducted in North Shewa, Debre Berhan town from April 1-30, 2020. Debre Berhan is located in the Semien Shewa Zone of the Amhara Region, about 130 kilometers northeast of Addis Ababa the town has an elevation of 2,840 meters above sea level.

All elderly population aged 60 years and above who were living in Debre Berhan North Shewa, Ethiopia.

\section{Sample Size Determination}

The sample size was determined by using two population proportion formula with the following assumptions: unexposed to an exposed ratio (r) of 1 , confidence level (a) 0.05 , power $80 \%$, the prevalence of malnutrition among depressed (P1) to be $59.7 \%$ and the prevalence malnutrition among non-depressed $(\mathrm{P} 2)$ to be $37.6 \%$. The prevalence is taken from a study conducted in South Africa. ${ }^{12}$ OpenEpi, version 2 was used to identify the sample size for each group, and based on these assumptions, the total sample size calculated was 347 .

\section{Sampling Procedures}

Simple random sampling technique was used to select 347 study participants from 1223 elderly age groups who were residents of 9 kebeles in Debre Berhan town by using proportion to population and final study participants were selected by simple random sampling from a sampling frame by using ENA SMART software for planning. The sampling frame was obtained from each kebeles health extension worker's family folder.

\section{Data Collection Methods}

For data collection from the elderly population an MNA tool and other factors were used in the form of a structured questionnaire that was translated into the local language of Amharic and conducted through face to face interviews during the survey. Focusing mainly on socio-economic and demographic status; health care services; common diseases and behavioral characteristics; and anthropometric measurements interviews were carried out by the MNA tool that focused on screening and assessments found in the Nestle Nutrition Institute. Using the MNA score participants are grouped as malnourished $(<17)$, at risk of malnutrition (17-23.5) or normal nutritional status (24-30) scores. ${ }^{13}$

Anthropometric measurements were done by; height measurement, portable height meter was used, and participants measured barefoot, standing in an upright position, with their heel, buttock, shoulder, and prominent occipital against the height meter board. Reading of height measurement was taken twice to the nearest $0.1 \mathrm{~cm}$. 
However, for those with kyphosis and who had difficulty standing in an upright position to measure their height, it was estimated using a regression equation (height $=b_{0}+b_{1}$ (arm-span) $-0.433 *$ sex $)$ from arm-span measurement and 59.30+0.63 (arm-span) - $(0.433 * \mathrm{sex})$; where female $=1$ and male $=0$ equation was used to estimate height of participants. ${ }^{14}$

Weight was measured with a portable digital weight scale (Seca-Germany 881-1021659 wt. scale) after being standardized with a known weight, and informing the subject to wear light clothes and be barefoot, read to the nearest $0.1 \mathrm{~kg}$. The BMI (body mass index) was calculated as weight $(\mathrm{kg}) /(\text { height }(\mathrm{m}))^{2}$ and categorized as $0=$ BMI less than 19, $1=$ BMI 19 to less than 21, $2=$ BMI 21 to less than 23 and $3=$ BMI 23 or greater. CC (calf circumference) was measured by non-elastic centimeter tape at the widest area of the calf below the knee and categorized as $0=$ less than $31 \mathrm{~cm}$ and $1=31 \mathrm{~cm}$ and above then measured by flexible non-elastic tape at the midpoint of the tibia two times and reading close to $0.1 \mathrm{~cm}$. Mid-arm circumference (MUAC) was measured with flexible non-elastic tape at the midpoint of the non-dominant arm between the tip of the acromion and the olecranon process classified based on MNA as $0=$ less than $21 \mathrm{~cm}, 0.5=21-22 \mathrm{~cm}$ and $1=$ above $22 \mathrm{~cm}$.

\section{Data Quality Control}

Three days of training were provided to the data collectors and supervisors on the data collection tool, the data collection procedure, and anthropometric measurements (height, weight, MUAC, CC). Then the questionnaire was pretested on $5 \%$ of the sample size out of the study area (Debre Sina). TEM was done by using ENA for SMART software to check the validity and the reliability of the anthropometric measurements of the data collectors and supervisors by taking 10 respondents from the pretest samples and measuring two times each respondent. For accuracy, the sum of the square of the differences between the enumerator values (weight $1+$ weight 2 ) and the supervisor values (weight $1+$ weight 2 ) is calculated and to check for systematic errors of the enumerators the number of positive and negative deviations was used. Double data entry was done by two data clerks and consistency of the entered data was cross-checked by comparing the two separately entered data on EpiData.

\section{Data Processing and Analysis}

The data were cleaned and coded manually, then double entry was done on EpiData statistical software version 3.1 and then exported to STATA14 statistical software for analysis, and the BMI of the respondents was computed by using STATA14 software.

Descriptive statistical analysis such as simple frequencies, measures of central tendency, and measures of variability was used to describe the socio-economic and demography characteristics of participants as well as health care services, feeding, diseases, and behavior of the elderly. Then the information was presented using frequencies, summary measures, tables, and figures.

Logistic regression serves to model a categorical dependent variable as a function of one or more independent variables. For this study, the dependent variable has three categories and it is as ordered $1=$ normal nourished, $2=$ at risk of malnutrition, 3 = malnourished. A proportional odds model is instrumental to model the ordinal dependent variable by defining the cumulative probabilities rather than the probability of an individual event. The proportional odds model estimates the odds of being at or below a level of the response variable. It considers the probability of that event and all events before it. The proportional odds model is the default ordinal logistic regression type provided by statistical software. ${ }^{15}$ The proportional odds assumption ( $\beta$ is independent of response level) may be too strict and needs testing. The GOLM adopts the parallel lines assumption for all outcome categories. That permits the slope coefficients to vary for each binary regression. The GOLM holds the nature of the proportional odds model (POM) by considering simultaneously the effects of a collection of independent variables through successive dichotomizations of the outcome.

\section{Ethical Considerations}

Before starting the data collection process, ethical clearance was secured from the Addis Ababa University Health Research Ethics Review Committee (IHRERC). Official letter was written from Addis Ababa University to Debre Berhan town administration.

Informed written consent was obtained from all the individuals that were capable of giving informed consent For those incapable of giving informed consent, informed consent was taken from the legally authorized representative after explaining the objective and benefits of the study, but these individuals were not included in the research study. Confidentiality of the study participants' information was also ensured according to the Declaration of Helsinki ethical code for human subjects. 


\section{Result}

In this study, a total of 341 elderly groups have participated with a response rate of $98.27 \%$. For descriptive parts, STATA commands "tab" and "summ" were used. The mean $( \pm \mathrm{SD})$ age of the participants was $69( \pm 0.39)$ years, at 95\% CI: $(68.12,69.66)$ among them 213 $(62.46 \%)$ were male and the rest were female, 237 $(69.50 \%)$ were married and living with their married partner the rest had a different form of marital status and from the total respondents $216(63.34 \%)$ have a formal educational status and $174(51.03 \%)$ of the participants were retired and had pensions, the rest have different work. When we come to the economic status, or wealth index, of the elderly population $112(32.84 \%)$ were categorized as poor, $116(34.02 \%)$ were categorized as medium and the remaining $113(33.14 \%)$ were classified as higher categories. Living arrangement and family size: 172 (50.44\%) of the elderly were living with $0-3$ family members and the remaining 169 (49.56\%) were living with 4 or more family members; 191 (56.0\%) were living with a married partner, 108 (31.7\%) with other caregivers and $42(12.3 \%)$ respondents were living alone.

From the total respondents $278(81.52 \%)$ have caregivers and from them 250 (89.93\%) were females and the rest were male. When we see the relations of a caregiver to the participants, 137 (49.28\%) were the married partner but the rest had a different relationship with the participant and the age of caregivers indicates that $88(31.65 \%)$ of the caregivers were aged 35 and below the remaining 190 $(68.35 \%)$ were above the age of 35 years. The education status of caregivers shows that $221(79.50 \%)$ have a formal education and the remaining $57(20.50 \%)$ have no formal education (Table 1).

\section{Behavioral Practice and Overall Health Conditions of the Elderly Population}

In this study behavioral variables were assessed, and it was found that few participants $23(6.74 \%)$ were cigarette smokers and $10(2.93 \%)$ currently smoke, on the another hand, when we see alcohol consumption, $72(21.11 \%)$ of the participants take alcohol, of them 16 (21.92\%), 26 $(35.62 \%)$, and $30(41.66 \%)$ individuals take alcohol daily, weekly, and occasionally, respectively.

When we come to the overall health conditions of participants, shows that $139(40.76 \%)$ visited health in the past 3 months with the following conditions, 68(19.94) for hypertension, $18(5.28 \%)$ for diabetes, $9(2.64 \%)$ for
Table I Socio-Demographic Characteristics of the Elderly Population in Debre Berhan Town, North Shewa, Ethiopia 2020. $\mathrm{n}=34 \mathrm{I}$

\begin{tabular}{|c|c|c|}
\hline Variables & Frequency & $\%$ \\
\hline \multicolumn{3}{|l|}{ Age of the respondent } \\
\hline Young 60-64 year & 105 & 30.79 \\
\hline Young old $65-74$ & 163 & 47.80 \\
\hline Aged and oldest-old above 75 & 73 & 21.41 \\
\hline \multicolumn{3}{|l|}{ Sex of the respondent } \\
\hline Male & 213 & 62.46 \\
\hline Female & 128 & 37.54 \\
\hline \multicolumn{3}{|l|}{ The religion of the respondent } \\
\hline Orthodox & 300 & 87.98 \\
\hline Others * & 41 & 12.02 \\
\hline \multicolumn{3}{|l|}{ Educational status of the respondent } \\
\hline Formal education and above & 216 & 63.34 \\
\hline No formal education & 125 & 36.66 \\
\hline \multicolumn{3}{|l|}{ Occupation of the respondent } \\
\hline Retired & 174 & 51.03 \\
\hline Merchant & 15 & 4.4 \\
\hline Farmer & 16 & 4.7 \\
\hline Others (other work) ${ }^{* *}$ & 136 & 39.9 \\
\hline \multicolumn{3}{|l|}{ Monthly income of the respondent } \\
\hline Yes & 268 & 78.59 \\
\hline No & 73 & 21.41 \\
\hline \multicolumn{3}{|l|}{ Wealth index } \\
\hline Low & 113 & 33.1 \\
\hline Medium & 114 & 33.4 \\
\hline High & 114 & 33.4 \\
\hline \multicolumn{3}{|l|}{ Family size of the respondent } \\
\hline 0-3 Family members & 172 & 50.44 \\
\hline 4 and above family members & 169 & 49.56 \\
\hline \multicolumn{3}{|l|}{ Living arrangement of the respondent } \\
\hline With married partner & 191 & 56.0 \\
\hline With other*** & 108 & 31.7 \\
\hline Alone & 42 & 12.3 \\
\hline \multicolumn{3}{|l|}{ Having caregiver } \\
\hline Yes & 278 & 81.52 \\
\hline No & 63 & 18.48 \\
\hline \multicolumn{3}{|l|}{ Relation to the caregiver } \\
\hline Marriage partner & 137 & 40.2 \\
\hline Children's & 105 & 30.8 \\
\hline Grand children's & 36 & 10.5 \\
\hline Others***** & 63 & 18.5 \\
\hline \multicolumn{3}{|l|}{ Sex of caregiver } \\
\hline Male & 28 & 10.07 \\
\hline Female & 250 & 89.93 \\
\hline
\end{tabular}

Notes: Others *Muslim, Protestant, Catholic; Other **Livestock production, No occupation; Other ***With relatives, servants; Other *****Relatives, non-relatives' volunteers, servants. 
Table 2 Behavioral Practice and Overall Health Care Visit in the Last Three Months Among the Elderly Population in Debre Berhan Town, North Shewa, Ethiopia, 2020. $n=34$ I

\begin{tabular}{|l|l|l|}
\hline Variables & Frequency & $\%$ \\
\hline $\begin{array}{l}\text { Cigarette smoking } \\
\text { Yes }\end{array}$ & 10 & \\
No & 331 & 2.93 \\
\hline $\begin{array}{l}\text { Past history of cigarette smoking } \\
\text { Yes }\end{array}$ & 23 & 97.07 \\
No & 318 & \\
\hline $\begin{array}{l}\text { Alcohol consumption } \\
\text { Yes }\end{array}$ & 72.74 \\
No & 269 & 93.26 \\
\hline Health care visit last 3 months & & \\
Yes & 139 & 21.11 \\
No & 202 & 78.89 \\
\hline
\end{tabular}

musculoskeletal problems and 8(2.35\%), 11(3.23\%), 71 (20.82\%) diagnosed for dyspepsia, diarial disease, for the other conditions respectively and the rest of 156 $(45.75 \%)$ does not know their diagnosis (Table 2).

\section{Geriatrics' Depression Status}

When we come to geriatric depression disorder among the elderly population. Based on the geriatric depression score $127(37 \%)$ have a normal status 51 (15\%) have severe depression, $102(30 \%)$ have mild depression and $61(18 \%)$ have moderate depression. When we see the comorbidity of malnutrition and depression from the total respondents $50(23.4 \%)$ individuals with a malnutrition problem also have depression and $112(52.3 \%)$ individuals who were at risk of malnutrition also have depression.

\section{MNA Tool Results of Elderly Populations}

Full MNA tools with 18 questions were applied and study participants who participated in this study were asked the following questions and gave their responses accordingly. Frequency of meal or food pattern in their daily base 256 (75.07\%) participants had 3 or more meals in their daily life, only $61(17.89 \%)$ of the elderly population consumed dairy products in their daily life, even during a non-fasting time or feast time, from the total respondents, $36(10.56 \%)$ had severely decreased food intake, that means less than $3 / 4$ of their full meal. When we come to fluid intake in their daily life 132 (38.71\%) of the participants have less than 3 cups daily and when we come to the personal view of their nutritional status $96(28.15 \%)$ of the participants considered themselves as malnourished (Table 3).

\section{Nutritional Status of the Elderly Population}

Based on MNA assessment the nutritional status of the elderly population was as follows: $21.1 \%, 95 \%$ CI: (16.4, 25.2) were malnourished, $49.3 \%, 95 \%$ CI: $(43.9,55.3)$ were at risk of malnutrition and $29.6 \%, 95 \%$ CI: (25.2, 34.9) were normal (Figure 1).

When we see the age classifications of nutritional status among elderly groups as follows; young (60-64 years) $14(13.3 \%)$ were malnourished, $50(47.6 \%)$ were at risk of malnutrition and $41(39.9 \%)$ were normally nourished, among young-old (65-74 years) 30 (18.4\%) were malnourished, $86(52.8 \%)$ were at risk of malnutrition and $47(28.8 \%)$ were normally nourished and those 75 years and above age groups (aged and oldest-old) 28 (38.4\%) were malnourished, $32(43.8 \%)$ were at risk of malnutrition and the rest $13(17.8 \%)$ were normally nourished (Figure 2).

\section{Parameter Estimation}

Both the models defined above were fitted to the data set using STATA (version 14). The variable selection was purposeful, and the first step is used to assess the parallel line assumption. Firstly, a POM was fitted with command "ologit" and then the "Brant" test was performed to evaluate the parallel assumption. The command "gologit2" was used to estimate the GOLM. The PPOM used to be estimated by the "gologit2" command with the autofit choice.

The proposed model namely the proportional odds model (POM) was applied for this study and the results of the application were herein discussed. In addition to the response and explanatory variables, STATA 14 "ologit" with "or" command was used for odds ratio determination.

The log-likelihood at each iteration, the log-likelihood increases because the goal is to maximize the loglikelihood. The number in the parenthesis indicates the degrees of freedom of the Chi-square distribution used to test the LR $X^{2}$ statistic and is defined by the number of predictors in the model. The value for log-likelihood of the fitted model is $=-319.92225$, which is used in the likelihood ratio chi-square test of whether all predictors' regression coefficients in the model are occurring at the same time zero and in tests of models. The likelihood ratio 
Table 3 Mini Nutritional Assessment Result of the Elderly Population in Debre Berhan Town North Shewa, Ethiopia. $\mathrm{n}=$ 341

\begin{tabular}{|c|c|c|}
\hline Variables & Frequency & Percentage \\
\hline $\begin{array}{l}\text { How many full meals do you eat daily? } \\
\text { I. Meal } \\
\text { 2. Meal } \\
\text { 3. Meal and above }\end{array}$ & $\begin{array}{l}7 \\
78 \\
256\end{array}$ & $\begin{array}{l}2.05 \\
22.87 \\
75.07\end{array}$ \\
\hline $\begin{array}{l}\text { Do you consume at least one dairy } \\
\text { product (milk, cheese, or yogurt)? } \\
\text { I. Yes } \\
\text { 2. No }\end{array}$ & $\begin{array}{l}61 \\
280\end{array}$ & $\begin{array}{l}17.89 \\
82.11\end{array}$ \\
\hline $\begin{array}{l}\text { Do you consume two or more } \\
\text { servings of legumes or eggs per week } \\
\text { I. Yes } \\
\text { 2. No }\end{array}$ & $\begin{array}{l}91 \\
250\end{array}$ & $\begin{array}{l}26.69 \\
73.31\end{array}$ \\
\hline $\begin{array}{l}\text { Do you eat meat, fish, or poultry } \\
\text { every day? } \\
\text { I. Yes } \\
\text { 2. No }\end{array}$ & $\begin{array}{l}47 \\
294\end{array}$ & $\begin{array}{l}13.78 \\
86.22\end{array}$ \\
\hline $\begin{array}{l}\text { Do you consume two or more } \\
\text { servings of fruit or vegetables per day? } \\
\text { I. Yes } \\
\text { 2. No }\end{array}$ & $\begin{array}{l}94 \\
247\end{array}$ & $\begin{array}{l}27.57 \\
72.43\end{array}$ \\
\hline $\begin{array}{l}\text { Has food intake declined over the } \\
\text { past } 3 \text { months? } \\
\text { I. Severe decrease } \\
\text { 2. Moderate decrease } \\
\text { 3. No decrease }\end{array}$ & $\begin{array}{l}36 \\
89 \\
216\end{array}$ & $\begin{array}{l}10.56 \\
26.10 \\
63.34\end{array}$ \\
\hline $\begin{array}{l}\text { How much fluid (water, juice, coffee, } \\
\text { tea, milk ...) were consumed per day? } \\
\text { I. Less than } 3 \text { cups } \\
\text { 2. } 0.3 \text { to } 5 \text { cups } \\
\text { 3. More than } 5 \text { cups }\end{array}$ & $\begin{array}{l}132 \\
154 \\
55\end{array}$ & $\begin{array}{l}38.71 \\
45.16 \\
16.13\end{array}$ \\
\hline $\begin{array}{l}\text { How was your mode of feeding? } \\
\text { 1. Severe difficulties feed by the } \\
\text { assistance } \\
\text { 2. Some difficulties feed without } \\
\text { assistance } \\
\text { 3. No problem and self-feed }\end{array}$ & $\begin{array}{l}7 \\
12 \\
322\end{array}$ & $\begin{array}{l}3.52 \\
94.43\end{array}$ \\
\hline $\begin{array}{l}\text { How can you perceive your } \\
\text { nutritional status? } \\
\text { I. Views self as being malnourished } \\
\text { 2. Uncertain of nutritional state } \\
\text { 3. No nutritional problem }\end{array}$ & $\begin{array}{l}96 \\
50 \\
195\end{array}$ & $\begin{array}{l}28.15 \\
14.66 \\
57.18\end{array}$ \\
\hline
\end{tabular}

(Continued)
Table 3 (Continued).

\begin{tabular}{|l|l|l|}
\hline Variables & Frequency & Percentage \\
\hline $\begin{array}{l}\text { In comparison with other people of } \\
\text { the same age, how does }\end{array}$ & & \\
Does the patient consider his/her & & \\
health status? & & \\
I. Not as good & 85 & 24.93 \\
2. Does not know & 189 & 55.43 \\
3. As good & 44 & 12.90 \\
4. Better & 23 & 6.74 \\
\hline Weight loss during the last 3 months & 108 & 31.67 \\
\hline
\end{tabular}

Mini Nutritional Assessment result of the elderly population in Debre Behan Town, North Shew Ethiopia. $n=34$ I continued table; 6

\begin{tabular}{|c|c|c|}
\hline $\begin{array}{l}\text { I. Weight loss greater than } 3 \mathrm{~kg} \\
\text { 2. Does not know } \\
\text { 3. Weight loss between I and } 3 \mathrm{~kg} \\
\text { 4. No weight loss }\end{array}$ & $\begin{array}{l}- \\
26 \\
207\end{array}$ & $\begin{array}{l}- \\
7.62 \\
60.70\end{array}$ \\
\hline $\begin{array}{l}\text { Mobility } \\
\text { I. Bed or chair bound } \\
\text { 2. Able to get out of bed/chair but } \\
\text { does not go out } \\
\text { 3. Goes out }\end{array}$ & $\begin{array}{l}- \\
29 \\
312\end{array}$ & $\begin{array}{l}- \\
8.50 \\
91.50\end{array}$ \\
\hline $\begin{array}{l}\text { Has suffered acute disease in the past } \\
3 \text { months } \\
\text { I. Yes } \\
\text { 2. No }\end{array}$ & $\begin{array}{l}111 \\
230\end{array}$ & $\begin{array}{l}32.55 \\
67.45\end{array}$ \\
\hline $\begin{array}{l}\text { Lives independently (not in a nursing } \\
\text { home or hospital)? } \\
\text { I. Yes } \\
\text { 2. No }\end{array}$ & $\begin{array}{l}341 \\
-\end{array}$ & $\begin{array}{l}100 \\
-\end{array}$ \\
\hline $\begin{array}{l}\text { Do you take more than } 3 \text { prescription } \\
\text { drugs per day? } \\
\text { I. Yes } \\
\text { 2. No }\end{array}$ & $\begin{array}{l}45 \\
296\end{array}$ & $\begin{array}{l}13.20 \\
86.80\end{array}$ \\
\hline $\begin{array}{l}\text { Do you have Pressure sores or skin } \\
\text { ulcers? } \\
\text { I. Yes } \\
\text { 2. No }\end{array}$ & $\begin{array}{l}- \\
341\end{array}$ & $\begin{array}{l}- \\
100.0\end{array}$ \\
\hline $\begin{array}{l}\text { Body Mass Index (BMI) } \\
\text { I. BMI of less than } 19 \\
\text { 2. BMI } 19 \text { to less than } 21 \\
\text { 3. BMI } 21 \text { to less than } 23 \\
\text { 4. BMI } 23 \text { or greater }\end{array}$ & $\begin{array}{l}63 \\
43 \\
67 \\
168\end{array}$ & $\begin{array}{l}18.48 \\
12.61 \\
19.65 \\
49.27\end{array}$ \\
\hline
\end{tabular}

(Continued) 
Table 3 (Continued).

\begin{tabular}{|l|l|l|}
\hline Variables & Frequency & Percentage \\
\hline $\begin{array}{l}\text { Mid-arm circumference (3I) in cm } \\
\text { I. MAC less than 2I }\end{array}$ & 50 & \\
2. MAC 2I to 22 & 19 & 14.66 \\
3. MAC greater than 22 & 272 & 79.77 \\
\hline $\begin{array}{l}\text { Calf circumference (8) in cm } \\
\text { O }=\text { CC less than 3I }\end{array}$ & 161 & \\
I = CC 3I or greater & 180 & 57.21 \\
\hline $\begin{array}{l}\text { Neuropsychological problems } \\
\text { O }=\text { Severe dementia or depression }\end{array}$ & 50 & \\
I = Mild dementia & 164 & 14.66 \\
2 = No psychological problems & 127 & 38.09 \\
\hline
\end{tabular}

chi-square (LR $X^{2}$ ) tests that at least one of the predictors' regression coefficient is not equal to zero.

The LR $X^{2}$ statistic was calculated by -2 (L (null model) $\mathrm{L}($ fitted model $))=-2((-353.79884)-(319.92225))=$ 387.67543, where L (null model) is from the log-likelihood of the model with no predictor variable (iteration 0 ) and L (fitted model) is the log-likelihood from the final iteration (assuming the model converged) with all the parameters.

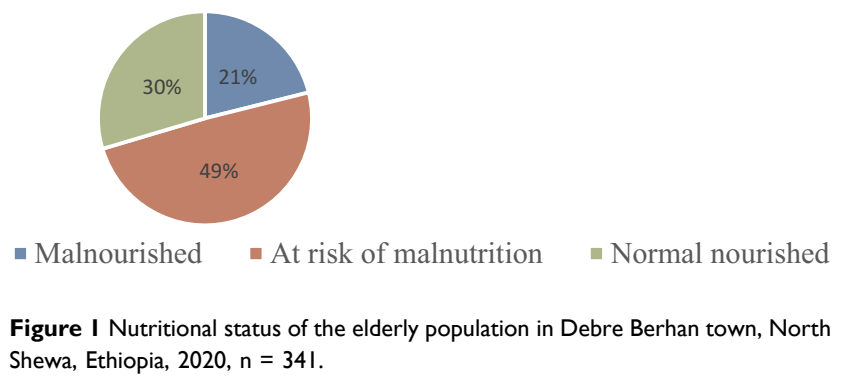

Then the odds ratio is determined by the "ologit" "or" command after all the above assumptions are checked. The P-value of the log-likelihood ratio Chi-square test with 12 degrees of freedom, LR $X^{2}(12)=67.75$, prob $>X^{2}=0.0000$, which indicates that at least one of the logit regression coefficients of the predictors were statistically different from 0 . So, the full model with all predictors provided a better fit than the null model.

\section{Predictors That Do Not Violate the Parallel Line Assumption for Elderly Population Nutritional Status}

The results of the POM revealed that holding all variables constant, as compared to female, a male was 2.03 (AOR = $2.03,95 \%$ CI: $1.13,3.63)$ times more likely to be at risk of malnourishment and malnutrition. Similarly, when we see living arrangements, compared to living with married partners, living with others was 3 ( $\mathrm{AOR}=3.00,95 \% \mathrm{CI}: 1.23$, 7.05) times more likely to be malnourished and at risk of malnutrition. When compared with the young (60-64 years) the old age and aged above 75 years were 2.58 $(\mathrm{AOR}=2.58,95 \% \mathrm{CI}: 1.34,4.99)$ times more likely to be at risk of malnutrition and have malnutrition. The odds of being at risk and malnourished were worse, 3.27 (AOR = $3.27,95 \%$ CI: $1.95,5.5)$ times higher among lower wealth index groups, as compared to higher wealth index groups, in a similar way not having a caregiver was a 2.21 (AOR = 2.21; 95\% CI: 1.14, 4.27)] times higher risk for risk of malnutrition and malnutrition compared to those who have a caregiver. When we come to alcohol consumptions, being an alcohol consumer make you 1.77 ( $\mathrm{AOR}=1.77$, 95\% CI: 1.04, 2.99) times more for being at risk for malnutrition and malnutrition, in a similar way education

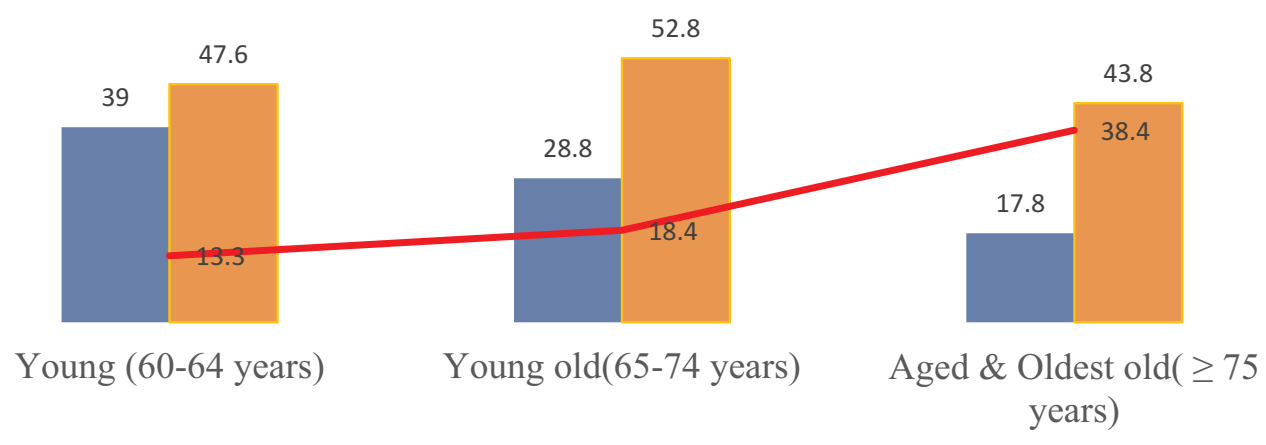

Normal nourished At risk of malnutrition -Malnourished

Figure 2 Distribution of nutritional status by age among the elderly population in Debre Berhan town, North Shewa, Ethiopia, 2020, $\mathrm{n}=34 \mathrm{l}$. 
status of respondents having no formal education was 2.06 $(\mathrm{AOR}=2.06,95 \%$ CI: 1.19, 3.57) times more to be at risk of malnutrition and malnutrition to the counterpart of having a formal education and when we see the depression status (AOR $=1.9,95 \%$ CI: 1.22, 2.94) leads to 1.9 times more likely to be at risk of malnutrition and malnutrition (Table 4).

\section{Discussion}

In this study, from the total participants of $341 ; 72$ (21.1\%) of them were malnourished, $168(49.3 \%)$ were at risk of malnutrition and the rest $101(29.6 \%)$ were normally nourished. Based on this finding we may conclude that the problem of malnutrition and the risk of malnutrition is highly prevalent in the study area, as shown above with the high prevalence of risk for malnutrition, if there is no early intervention this may raise the prevalence of malnutrition. When we come to geriatric depression disorder among the elderly population. Based on the geriatric depression score $214(62.8 \%)$ has the depressive disorder; of them, $53(24.7 \%), 62(28.9 \%)$, and $99(46.3 \%)$ have severe, moderate and mild depression disorder respectively.

For this study in the ordinal regression after adjusting for some independent variables; sex being male, age of the respondent being aged and oldest-old above 75 years, living with others, not having a caregiver, educational status with no formal education, wealth index being in a low category, having depression disorder and alcohol consumption are all linked with elderly malnutrition and being at risk for malnutrition.

When we compare the findings of this study with other similar studies, in this study $21.1 \%$ of the elderly population was malnourished when compared to other similar international studies this study is higher than a study conducted in Turkey revealing that $19 \%$ of old age group has malnutrition, in the Netherland $17 \%$ were malnourished ${ }^{16}$ another cross-sectional study in Bogotá, Colombia showed

Table 4 Ordinal Logistic Regression Model Predicting the Parameters of At Risk of Malnutrition and Malnutrition by Using Proportional Odds Model Among the Elderly Population in Debre Berhan Town, Ethiopia, 2020

\begin{tabular}{|c|c|c|c|c|c|}
\hline \multirow[t]{2}{*}{ Parameters } & \multicolumn{5}{|c|}{ At the Risk of Malnutrition and Malnourished versus Normal Nutritional Status } \\
\hline & Coefficient & Std. Error & $\mathbf{Z}$ & $\mathbf{P}>\mathbf{z}$ & Odds Ratio at $95 \% \mathrm{Cl}$ for $\mathrm{AOR}$ \\
\hline Cat I & 2.101 & 0.554 & & & $2.10(1.02,3.19)$ \\
\hline Cat 2 & 4.651 & 0.603 & & & $4.65(3.47,5.83)$ \\
\hline \multicolumn{6}{|l|}{ Sex } \\
\hline Male & 0.706 & 0.298 & 2.37 & 0.018 & $2.03(1.13,3.63)$ \\
\hline \multicolumn{6}{|l|}{ Age of respondent } \\
\hline young old, 65-74 year & 0.4640 & 0.253 & 1.83 & 0.067 & $1.59(0.97,2.61)$ \\
\hline old age and aged above 75 year & & & & & \\
\hline Wealth index. & 0.9487 & 0.336 & 2.82 & 0.005 & $2.58(1.34,4.99)$ \\
\hline Medium wealth index & 0.6001 & 0.269 & 2.23 & 0.026 & $1.82(1.08,3.09)$ \\
\hline \multicolumn{6}{|l|}{ Lower wealth index } \\
\hline Caregiver & 1.1857 & 0.265 & 4.48 & 0.000 & $3.27(1.95,5.50)$ \\
\hline Has no caregiver & 0. 7897 & 0.338 & 2.34 & 0.019 & $2.21(1.14,4.27)$ \\
\hline Living arrangement. & 1.127 & 1.301 & 2.67 & 0.007 & $3.00(1.23,7.05)$ \\
\hline Living with others living alone & 0.6570 & 0.7508 & 1.69 & 0.091 & $1.93(0.90,4.14)$ \\
\hline \multicolumn{6}{|l|}{ Family size. } \\
\hline 4 and above family members & 0.1060 & 0.2568 & 0.46 & 0.646 & I.II(0.7I, I.75) \\
\hline Alcohol consumption. & & & & & \\
\hline Yes & 0.5696 & 0.2693 & 2.11 & 0.034 & $1.77(1.04,2.99)$ \\
\hline \multicolumn{6}{|l|}{ Respondent education. } \\
\hline No formal education & 0.7224 & 0.2804 & 2.58 & 0.010 & $2.06(1.19,3.57)$ \\
\hline \multicolumn{6}{|l|}{ Geriatric Depression Score. } \\
\hline Has depression & 0.6398 & 0.2242 & 2.85 & 0.004 & $1.90(1.22,2.94)$ \\
\hline
\end{tabular}


that $4.58 \%$ were malnourished. ${ }^{17}$ This difference may be caused by socio-economic differences where it is known that Ethiopia is one of the third world countries, so this makes the change in the prevalence of elderly malnutrition. When we compare to other national studies this study is higher than a study conducted in Wolayita Sodo that shows the prevalence of malnutrition is $17.1 \%$ and Gondar Ayekel town reveals that prevalence of malnutrition was $17.6 \% .^{18,19}$

This difference in magnitude may be due to an assessment tool difference and sample size, for instance, the study done in Gonder has used BMI as a measurement tool for elderly malnutrition and the study in Wolayita Sodo has used contextualized MNA as a measurement tool but in this study, we have used the full form of MNA.

However, the findings of this study are smaller than some other local studies in Debra Markos that reveal undernutrition among the elderly was $22.7 \%{ }^{20}$ and another study in Hawassa town shows that the prevalence of malnutrition among elderly shows at $28.3 \%$. ${ }^{6}$ This difference may be caused by study time the above two studies were conducted 5 years and 8 years back respectively as this study is a recent study there may be an improvement, otherwise Debre Merkos and Debre Berhan have nearly the same setups except the altitude difference.

The findings from this study are comparable with similar studies that have been conducted in India showing that $20.8 \%$ of respondents were malnourished and a study conducted in Gondar shows that the prevalence of malnutrition was $21.9 \%$ in elderly people. ${ }^{18,21}$ This similarity may be due to study timing, both studies were recently conducted, and another similarity may be due to similar study design and that the study conducted in India used similar data collection tools that mean full MNA that may the source of similarity with this study.

This study reveals that from the total respondents 168 $(49.3 \%)$ were at risk of malnutrition; When we compare with other local studies that were conducted in Hawassa town for tool validation revealing that $62.4 \%$ of the elderly population were at risk of malnutrition. ${ }^{6}$ This prevalence is higher than this study this may be due to study setup difference as we know that the two towns are different, Hawassa is a regional town but Debre Berhan is a zonal town, this may make a change in life stress level and change the risk of malnutrition prevalence.

But a finding of this study was higher than other international studies; in Bogotá, Colombia which shows $34.27 \%$ were at risk of malnourishment, ${ }^{17}$ a study done in southern India, where $32.5 \%$ were at risk of malnutrition $^{22}$ and a study in the similar area done, shows that $24.73 \%$ were at risk from malnutrition. ${ }^{23}$ This difference may be caused by socio-economic and health facility setup differences as we know that the abovementioned countries have better health and economic setups compared to this study.

In this study the risk of being malnourished is 2.03 times higher among male old age groups compared to female groups. Another similar study in line with this study that was conducted in South Africa reveals that male groups were more malnourished and at-risk when compared to female groups. ${ }^{12}$ This may reflect the commonalities of the problem throughout the globe and that may also suggest that male old age groups need more care and attention as their age increases.

However other similar studies that were conducted in Ethiopia in Gonder and Debre Merkos reveal that being female is associated with elderly malnutrition. ${ }^{20,24}$ This difference may be because of the analytic model in this study where an ordinal logistic regression is conducted however the above mentioned two studies used multivariable binary logistic regression, also they merged malnutrition and risk for malnutrition together, unlike this study.

Another factor that is linked with malnutrition is the age of the respondent, being aged and oldest-old above 75 years increases the risk of being malnourished by 2.58 times among elderly groups compared with younger old age groups (60-64). This finding is constant with other studies that were conducted in Gonder and Debre Markos showing that elders were more likely malnourished compared to young-old (60-64 years). ${ }^{20,24}$ This similarity may show the commonalities of the problem in two areas and when the age of the person increases the prevalence of malnutrition also increase.

Of the identified factors, educational status was found statically significant for malnutrition for elderly populations. Those respondents with no formal education were 2.06 times more likely affected by malnutrition as compared to those who have a formal education. This finding is in line with studies conducted in Banga, India and Turkey which show a low literacy level being more exposed to malnutrition. ${ }^{9,25}$ This reason may be due to those with no formal education having a low understanding of their health which may focus on their meal, food diversity, feeding habits, and the effect of malnutrition on their lifestyle. 
On the other hand, respondents with a low category of wealth index level suffer a high burden of malnutrition which was 3.27 times more compared to the higher categories. This finding is also supported by other local studies that were conducted in Gonder town and Gonder Ayekel town shows that having poor household wealth status is highly exposed to malnutrition. ${ }^{18,24}$ This reason may be due to poor elders having no adequate amount of food to eat and having a relatively low lifestyle as compared to higher ones, and in which they always have trouble securing daily food intake. Moreover, the low living standard at a household level may expose family members to a low quantity and quality of foods as well as poor health care.

Depression is also another identified risk factor for elder's malnutrition and the risk of malnutrition, in which depressed elders were 1.90 times more likely to suffer from malnutrition and risk of malnutrition than those not depressed. This finding is in line with studies done in South Africa and Norway that reveal depressed elders were more likely to be at risk or be malnourished than those not depressed ${ }^{26,27}$ and also the same with the study done in the Netherlands that reveals depression was independently associated with an increased risk of malnutrition. ${ }^{16}$ This may be because an individual who is depressed is more likely to be living in stressful situations and life burdened that means by one way or another the nutritional condition of the elderly is altered by depression. In a similar way in this study alcohol consumption is significantly associated with the nutritional status of the elderly population and the risk of malnutrition among alcohol consumers is 1.77 times higher than that of non-alcohol consumers. And the finding of this study is in line with the study done in Sri Lanka that shows alcohol consumption was positively associated with malnutrition. ${ }^{28}$ This similarity may be because alcohol consumption may be due to stressful conditions and that again results in malnutrition as the above reality indicated that depression results in malnutrition.

In this study, again, living arrangements with other than married partners increase the risk of malnutrition by 3.0 times in comparison with the elderly population living with a married partner. This study is in line with the study done in India that found living arrangements without a spouse and children were significantly associated with elderly malnutrition. ${ }^{29}$ This may be because of a caregivers' relation to the elder matters more and at this age level, the better caregiver is a related one.

In a similar way, not having a caregiver increases the risk of malnutrition by 2.21 times. As we have searched the literature on this topic there are no other comparator studies on this variable. But this association is maybe caused by the fact that a lack of a caregiver will expose the elder to malnutrition.

As this study was an ordinal logistic regression as being at risk of malnutrition and malnourished state compared to a normal nutritional status the above variables were associated. However, no comparator studies have been seen for the risk of malnutrition. And the above association may be because individuals who were malnourished previously passed the stage of being at risk for malnutrition.

\section{Limitations of the Study}

Due to a shortage of time and resource this study is limited to only urban areas and this means the difficulty of generalizations and conclusions are only limited to the urban setting.

\section{Conclusion}

In conclusion from the total participants, one-fifth of the participants were malnourished and around half of the participants were at risk of malnutrition and more than half of the total participants have geriatric depression. Sex, age of the respondent, living with others, not having a caregiver, educational status, wealth index, depression disorder, and alcohol consumption were all linked with elderly malnutrition and the risk of malnutrition.

\section{Recommendations}

Therefore; intervention on an age-friendly social support system, social networking, nutrition intervention, and screening of malnutrition may enhance early detection and management of nutritional problems among the elderly.

\section{Disclosure}

The authors report no conflicts of interest for this work.

\section{References}

1. Encyclopedia.com. Aging of Population. Encyclopedia of population. 2020.

2. Skirbekk VF, Staudinger UM, Cohen JE. How to measure population aging? The answer is less than obvious: a review. Gerontology. 2019;65:136-144. doi:10.1159/000494025

3. CIA. World factbook Ethiopia life expectancy at birth - demographics. IndexMundi [Internet]; 2019.

4. United Nations DoE, Social Affairs PD. World population prospects 2019: highlights (ST/ESA/SER. A/423). United Nations New York; 2019.

5. Charles T, Tesfaye G, Hassan A, Population dynamics. Addi Ababa: Food/Nutrition Security and Health in Ethiopia; 2009.

6. Hailemariam H, Singh P, Fekadu T. Evaluation of mini nutrition assessment (MNA) tool among community-dwelling elderly in an urban community of Hawassa city, Southern Ethiopia. BMC Nutrition. 2016;2(1):11. doi:10.1186/s40795-016-0050-1 
7. Corish CA, Kennedy NP. Protein-energy undernutrition in hospital in-patients. $B r J$ Nutr. 2000;83(6):575-591. doi:10.1017/S000711450 000074X

8. Stratton RJ, King CL, Stroud MA, Jackson AA, Elia M. 'Malnutrition Universal Screening Tool' predicts mortality and length of hospital stay in acutely ill elderly. Br J Nutr. 2006;95(2):325-330. doi:10.1079/BJN20051622

9. Gündüz E, Eskin F, Gündüz $M$, et al. Malnutrition in community-dwelling elderly in Turkey: a multicenter, cross-sectional study. Med Sci Mon. 2015;21:2750. doi:10.12659/ MSM.893894

10. Kim J, Lee Y, Won C, Lee K, Chon D. Nutritional status and frailty in community-dwelling older Korean adults: the Korean Frailty and Aging Cohort Study. J Nutr Health Aging. 2018;22(7):774-778. doi:10.1007/s12603-018-1005-9

11. Santos AL, Amaral TM, Borges NP. Undernutrition and associated factors in a Portuguese older adult community. Revista De Nutrição. 2015;28(3):231-240. doi:10.1590/1415-52732015000300001

12. Naidoo I, Charlton KE, Esterhuizen TM, Cassim B. High risk of malnutrition associated with depressive symptoms in older South Africans living in KwaZulu-Natal, South Africa: a cross-sectional survey. J Health Popul Nutr. 2015;33(1):19. doi:10.1186/s41043015-0030-0

13. NNI. Mini nutritional assessment MNA. 2009.

14. Dessie A, Argaw A, Belachew T. Developing an equation for estimating body height from linear body measurements of Ethiopian adults. J Physiol Anthropol. 2018;37(1):1-8.

15. Chatfield C, Zidek J, Lindsey J. An Introduction to Generalized Linear Models. New York, Washington, DC: Chapman and Hall/ CRC; 2010.

16. Lonterman-Monasch S, de Vries OJ, Danner SA, Kramer MH, Muller M. Prevalence and determinants for malnutrition in geriatric outpatients. Clin Nutr. 2013;32(6):1007-1011. doi:10.1016/j.clnu. 2013.05.007

17. Chavarro-Carvajal D, Reyes-Ortiz C, Samper-Ternent R, Arciniegas AJ, Gutierrez CC. Nutritional assessment and factors associated with malnutrition in older adults: a cross-sectional study in Bogotá, Colombia. J Aging Health. 2015;27(2):304-319. doi:10.1177/0898264314549661

18. Legesse M, Abebe Z, Woldie H. Chronic energy deficiency and associated factors among the older population in Ethiopia: a community-based study. PLoS One. 2019;14(4):e0214861. doi:10.1371/journal.pone.0214861
19. Wondiye K, Asseffa NA, Gemebo TD, Astawesegn FH. Predictors of undernutrition among the elderly in Sodo zuriya district Wolaita zone, Ethiopia. BMC Nutrition. 2019;5:50. doi:10.1186/s40795-019-0320-9

20. Adhana Z, Tessema G, Getie G Prevalence of under nutrition and associated factors among people of old age in Debre Markos Town, Northwest Ethiopia, 2015.

21. Joymati O, Ningombam M, Rajkumari B, Gangmei A. Assessment of nutritional status among the elderly population in a rural area in Manipur: a community-based cross-sectional study. Int J Community Med Public Health. 2018;5(7):3125-3129. doi:10.18203/2394-6040. ijcmph20182660

22. Konda S, Giri PA. Prevalence of malnutrition and its determinants in elderly people in South India. Int J Community Med Public Health. 2018;5(8):3570-3576. doi:10.18203/2394-6040.ijcmph20183100

23. Mathew AC, Das D, Sampath S, Vijayakumar M, Ramakrishnan N, Ravishankar S. Prevalence and correlates of malnutrition among elderly in an urban area in Coimbatore. Indian J Public Health. 2016;60(2):112. doi:10.4103/0019-557X.184542

24. Tessfamichael D, Gete AA, Wassie MM. High prevalence of undernutrition among elderly people in Northwest Ethiopia: a cross-sectional study. Read Write. 2014;244:32.2.

25. Lahiri S, Biswas A, Santra S, Lahiri SK. Assessment of nutritional status among the elderly population in a rural area of West Bengal, India. Int J Med Sci Public Health. 2015;4(4):569-572. doi:10.5455/ ijmsph.2015.20122014117

26. Cho J, Jin Y, Kang H. Weight status, physical activity, and depression in Korean older adults. J Epidemiol. 2018;JE20170083.

27. Kvamme J-M, Grønli O, Florholmen J, Jacobsen BK. The risk of malnutrition is associated with mental health symptoms in community-living elderly men and women: the Tromsø Study. BMC Psychiatry. 2011;11(1):112. doi:10.1186/1471-244X-11-112

28. Damayanthi H, Moy FM, Abdullah KL, Dharmaratne SD. Prevalence of malnutrition and associated factors among community-dwelling older persons in Sri Lanka: a cross-sectional study. BMC Geriatr. 2018;18(1):199. doi:10.1186/s12877-018-0892-2

29. Ramya M, Ranganath T, Jadhav J, Swetha N. To assess the nutritional status among elderly and factors influencing it, in an urban area, Bengaluru-a cross-sectional study. Int J Community Med Public Health. 2017;4(5):1727-1732. doi:10.18203/2394-6040.ijcmph20171792

30. CSA, ORC Macro. Ethiopia demographic and health survey key indicators report. Addis Ababa, Ethiopia, Rockville, Maryland: Central Statistical Authority; 2017.
Nutrition and Dietary Supplements

\section{Publish your work in this journal}

Nutrition and Dietary Supplements is an international, peerreviewed, open access journal focusing on research into nutritiona requirements in health and disease, impact on metabolism and the identification and optimal use of dietary strategies and supplements necessary for normal growth and development. The journal welcomes submitted papers covering original research, basic science, clinical \& epidemiological studies, reviews and evaluations, guidelines, expert opinion and commentary, case reports and extended reports. The manuscript management system is completely online and includes a very quick and fair peer-review system, which is all easy to use. Visit http://www.dovepress.com/testimonials.php to read real quotes from published authors. 